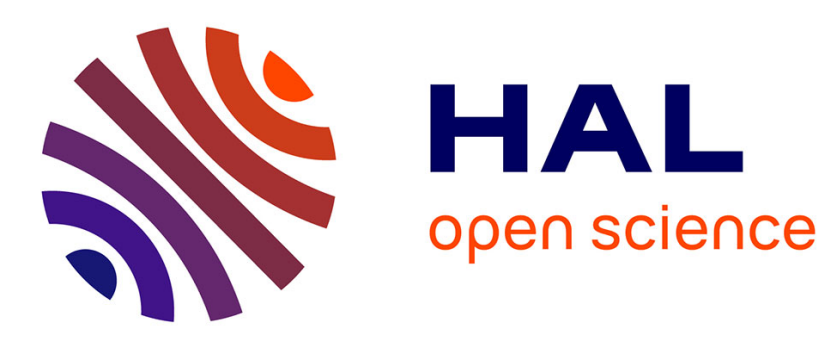

\title{
Novel contributions on luminescent apatite-based colloids intended for medical imaging
}

\author{
Ahmed Al-Kattan, Véronique Santran, Pascal Dufour, Jeannette
}

Dexpert-Ghys, Christophe Drouet

\section{- To cite this version:}

Ahmed Al-Kattan, Véronique Santran, Pascal Dufour, Jeannette Dexpert-Ghys, Christophe Drouet. Novel contributions on luminescent apatite-based colloids intended for medical imaging. Journal of Biomaterials Applications, 2014, vol. 28, pp. 697-707. 10.1177/0885328212473510 . hal-01073123

\section{HAL Id: hal-01073123 \\ https://hal.science/hal-01073123}

Submitted on 9 Oct 2014

HAL is a multi-disciplinary open access archive for the deposit and dissemination of scientific research documents, whether they are published or not. The documents may come from teaching and research institutions in France or abroad, or from public or private research centers.
L'archive ouverte pluridisciplinaire HAL, est destinée au dépôt et à la diffusion de documents scientifiques de niveau recherche, publiés ou non, émanant des établissements d'enseignement et de recherche français ou étrangers, des laboratoires publics ou privés. 


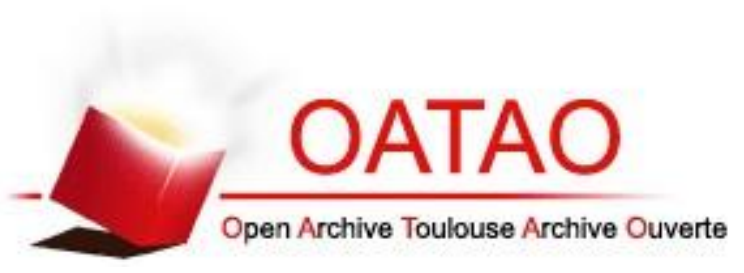

Open Archive Toulouse Archive Ouverte (OATAO)

OATAO is an open access repository that collects the work of Toulouse researchers and makes it freely available over the web where possible.

This is an author-deposited version published in: http://oatao.univ-toulouse.fr/ Eprints ID: 12048

Identification number: DOI : $10.1177 / 0885328212473510$

Official URL: http://dx.doi.org/10.1177/0885328212473510

\section{To cite this version:}

Al-Kattan, Ahmed and Santran, Véronique and Dufour, Pascal and DexpertGhys, Jeannette and Drouet, Christophe Novel contributions on luminescent apatite-based colloids intended for medical imaging. (2014) Journal of Biomaterials Applications, vol. 28 ( ${ }^{\circ}$ 5). pp. 697-707. ISSN 0885-3282

Any correspondence concerning this service should be sent to the repository administrator: staff-oatao@inp-toulouse.fr 


\title{
Novel contributions on luminescent apatite-based colloids intended for medical imaging
}

\author{
Ahmed Al-Kattan', Veronique Santran², Pascal Dufour', \\ Jeannette Dexpert-Ghys ${ }^{3}$ and Christophe Drouet'
}

\begin{abstract}
The setup of colloidal hybrid nanosystems based on biomimetic calcium phosphate apatites doped with europium ions has recently raised great interest in the pharmacological community, especially due to their bio-inspired character. This is especially relevant in relation with medical imaging for cancer diagnosis. Questions however remain in relation to a number of applicability aspects, some of which have been examined in this contribution. In a first part of this work, we explored further the luminescence properties of such colloidal nanoparticles. We pointed out, upon excitation of europium, the existence of some non-radiative de-excitation via the vibration of $\mathrm{O}-\mathrm{H}$ oscillators located at the vicinity of the $\mathrm{Eu}^{3+}$ luminescent centers. The replacement of $\mathrm{Eu}^{3+}$ by $\mathrm{Tb}^{3+}$ ions, less prone to non-radiative de-excitation, was then tested in a preliminary way and can be seen as a promising alternative. In a second part of this work, we inspected the possibility to store these colloids in a dry state while retaining a re-suspension ability preserving the nanometer size of the initial nanoparticles, and we propose a functional protocol involving the addition of glucose prior to freeze-drying. We finally showed for the first time, based on titrations of intracellular $\mathrm{Ca}^{2+}$ and $\mathrm{Eu}^{3+}$ ions, that folic acid-functionalized biomimetic apatite nanoparticles were able to target cancer cells that overexpress folate receptors on their membrane, which we point out here in the case of T-47-D breast carcinoma cells, as opposed to ZR-75-I cells that do not express folate receptors. This contribution thus opens new exciting perspectives in the field of targeted cancer diagnosis, thus confirming the promise of biomimetic apatites-based colloidal formulations.
\end{abstract}

\section{Keywords}

Bionanotechnology, materials-cells interactions, colloids, hybrid materials, luminescence, cancer, biomimetic apatites, hydroxyapatite

\section{Introduction}

Today, the use of engineered biotechnological nanosystems such as gold nanoparticles, ${ }^{1}$ quantum dots, ${ }^{2}$ polymer-based nanospheres, ${ }^{3}$ liposomes, ${ }^{4}$ and more recently biomimetic apatite-based hybrid nanoparticles, ${ }^{5-7}$ among other systems, is considered a promising approach in view of tailored diagnosis and/or treatment applications, especially in link with cancer pathologies. The fate of such nanosystems once in vivo as well as their biocompatibility is however of continual concern, whether these nanosystems are envisioned for diagnosis aspects or for therapeutic applications (localized drug delivery). Also, these systems become all the more appealing that they exhibit a targeting activity towards specific types of cells or tissues. Such nanosystems able to target specifically cancer cells need to comply with several characteristics including biocompatibility, the possibility to control their size in the nanometer scale (typically under $100 \mathrm{~nm}$ ), and the possibility to functionalize their surface with a cell-targeting agent (e.g. peptides, vitamins, antibodies...).

Nanosystems inspired from nature itself are bound to be especially well-suited to nanomedicine

\footnotetext{
'CIRIMAT Carnot Institute, UMR CNRS/INPT/UPS, University of Toulouse, France

${ }^{2}$ Icelltis, Prologue I, Labège, France

${ }^{3}$ CEMES, University of Toulouse, France
}

\section{Corresponding author:}

Christophe Drouet, CIRIMAT Carnot Institute, UMR CNRS/INPT/UPS, University of Toulouse, 4 allee Emile Monso, Ensiacet, Toulouse cedex 4, 31030 , France.

Email: christophe.drouet@ensiacet.fr 
applications taking into account their intrinsic biocompatibility, which explains the ever-growing load of work being investigated worldwide in this domain. Among bio-inspired nanosystems, those based on calcium phosphate biomimetic apatites (similar to those already found in the body in bone mineral) appear as promising candidates due to the ability to tailor and exploit their exceptional surface properties enabling in particular various types of surface functionalization. $^{8-12}$ Previous works showed the possibility to synthesize, by a soft chemistry route starting from easily handled ionic salts, some luminescent colloidal nanoprobes based on europium-doped biomimetic apatite nanoparticles, dedicated to medical imaging, and demonstrated several benefits: (1) these systems are based on bio-inspired and exhibit a structure that allows several ionic substitutions (e.g. $\left.\mathrm{Ca}^{2+} / \mathrm{Eu}^{3+}\right)^{7,13}$ as well as a functionalizable surface; (2) it is possible to obtain colloid-like suspensions, for instance upon surface grafting of a phospholipid moiety (2-aminoethylphosphoric acid, AEP) ${ }^{14}$ that is also biocompatible as already present on the surface of human cells; (3) the mean nanoparticle size in suspension can be controlled down to about $30-40 \mathrm{~nm}$ by the amount of grafted AEP on the surface of apatite particles; ${ }^{7}$ these systems exhibit a long luminescence lifetime (close to $1 \mathrm{~ms})^{7}$ allowing long analyses of biological tissues, possibly through time-resolved luminescence techniques. Also, a recent study showed the possibility to functionalize such apatite-based hybrid nanoparticles by a targeting agent: folic acid (B9 vitamin), a tumor cell marker, thus opening potential perspectives for cancer targeting. ${ }^{5}$ Preliminary biological tests were also initiated in order to better understand the nanoparticles-immunological system (typically human monocytes) interaction, and no pro-inflammatory potential was detected for such colloidal nanoparticles at the concentrations used for detection. In addition, cytotoxicity measurements pointed out their low cytotoxicity, thus allowing their potential use in biomedical applications. ${ }^{5}$ Finally, in vitro experiments revealed that such nanoparticles were internalizable (possibly via endocytosis) by ZR-75-1 breast carcinoma cells. ${ }^{5}$

Although the above-mentioned results stress the promise of such biomimetic apatite-based nanosystems in nanomedicine, some aspects still remain to be explored further. Of particular relevance is a further exploration of their luminescence properties, in view of a possible optimization. Another point of interest would be related to the possibility to store such suspensions for extended periods of time without alteration (e.g. particle size evolution with time). Finally, the cell-targeting ability of such nanoparticles still has to be investigated so as to examine the possibility to target specifically some types of cancer cells. In this paper, we explore these three aspects and discuss our results in link with possible upcoming applications in nanomedicine and more specifically concerning the field of nano-oncology.

\section{Materials and methods}

\section{Preparation of apatite colloidal suspensions}

The synthesis protocol used in this work for preparing apatite-based colloids is described in detail in our precedent work. ${ }^{7}$ Briefly, three starting aqueous solutions are prepared: solution (A) consisting in a mixture of calcium and europium (or terbium as indicated in the text) nitrates. The $\mathrm{Ln} /(\mathrm{Ca}+\mathrm{Ln})$ mole ratio, where $\mathrm{Ln}$ stands for the lanthanide ions used $\left(\mathrm{Eu}^{3+}\right.$ or $\left.\mathrm{Tb}^{3+}\right)$, was set here to $1.5 \mathrm{~mol} \%$. The total $\mathrm{Ca}+\mathrm{Ln}$ amount in solution (A) was $4.87 \mathrm{mmol}$ dissolved in $6.25 \mathrm{ml}$ of deionized water. The second solution, named (B), was obtained by dissolving $4.87 \mathrm{mmol}$ of AEP in $6.25 \mathrm{ml}$ of deionized water. Finally, solution (C) was composed of $1.62 \mathrm{mmol}$ of ammonium hydrogénophosphate dissolved in $12.5 \mathrm{ml}$ of deionized water. Solution (A) was added under stirring to solution (B) and the $\mathrm{pH}$ of the mixture was adjusted to 9.5. The $\mathrm{pH}$ of solution (C) was also adjusted to 9.5 and added to the previous mixture. The suspension was then introduced in an oven preset at $100^{\circ} \mathrm{C}$, for $16 \mathrm{~h}$, for an ageing step. The colloidal suspension obtained was then purified by dialysis process as detailed elsewhere. ${ }^{15}$ The final $\mathrm{pH}$ of the suspension was then reduced to physiological value $(\mathrm{pH} \sim 7.4)$ by addition of ca. $3 \mathrm{ml}$ of sodium hexametaphosphate (HMP) at a concentration of $0.08 \mathrm{M}$.

For studying re-dispersion aspects, an addition of glucose (as mentioned in the text) has been made in the colloidal suspensions (purified by dialysis and treated with HMP, as mentioned above) prior to freezedrying. Three concentrations of glucose were tested, $3.7,11.1$, and $18.5 \mathrm{mg} / \mathrm{ml}$ (corresponding respectively to the introduction of 50,150 , and $250 \mathrm{mg}$ of glucose in $13.5 \mathrm{ml}$ of colloid composed of $12 \mathrm{ml}$ of colloid and $1 \mathrm{ml}$ of HMP solution at $0.08 \mathrm{M})$ ); and the re-suspension was performed after freeze-drying by addition of $13.5 \mathrm{ml}$ of deionized water and sonification during $10 \mathrm{sec}$.

\section{Association with folic acid}

When mentioned in the text, folic acid (denoted "FA") was added in the reacting medium precisely in the same time of the preparation of solution (A). The FA concentration used was typically $0.45 \mathrm{mM}$. The rest of the synthesis remained unchanged. 


\section{Physico-chemical characterizations}

The crystallographic structure of the nanoparticles was checked, after freeze-drying, by X-ray diffraction (XRD) using a CPS 120 INEL diffractometer with the $\mathrm{K}_{\alpha 1}$ cobalt radiation $(\lambda=1.78892 \AA)$. Fourier-transform infrared (FTIR) analyses were performed using a Nicolet 5700 spectrometer. The wavenumber analysis window was set to $400-4000 \mathrm{~cm}^{-1}$, with a resolution of $4 \mathrm{~cm}^{-1}$. The particle size (hydrodynamic diameter, $\mathrm{D}_{\mathrm{h}}$ ) of the colloids was determined by dynamic light scattering (DLS) with a Nanosizer ZS apparatus from Malvern Instruments $(\lambda=630 \mathrm{~nm})$. The dispersion of the data points is estimated to $0.5 \%$. The same apparatus was used for zeta potential measurements, using a capillary cell, by a combination of electrophoresis and Laser Doppler velocimetry (allowing the measurement of the particle velocity in the liquid phase when an electrical field is applied).

The luminescence properties of the colloids doped with $\mathrm{Tb}^{3+}$ and $\mathrm{Eu}^{3+}$ were investigated using a Horiba Jobin Yvon Fluorolog 3-11 spectrofluorometer equipped with a $450 \mathrm{~W}$ xenon lamp. Excitation and emission were measured at room temperature directly on the colloidal suspensions, after dialysis. Concerning $\mathrm{Eu}^{3+}$, excitation spectra were recorded between $350 \mathrm{~nm}$ and $600 \mathrm{~nm}$ by monitoring the $\left[\mathrm{Eu}^{3+}\right]{ }^{5} \mathrm{D}_{0} \rightarrow{ }^{7} \mathrm{~F}_{2}$ emission at $\lambda_{\mathrm{em}}=612 \mathrm{~nm}$ (spectral bandwidth $=2 \mathrm{~nm}$ ). Emission spectra were recorded in the $500-700 \mathrm{~nm}$ range, with spectral bandwidth of $1 \mathrm{~nm}$, under selected excitation in the $\left[\mathrm{Eu}^{3+}\right]{ }^{7} \mathrm{~F}_{0} \rightarrow{ }^{5} \mathrm{~L}_{6}$ of $\mathrm{Eu}^{3+}$ at $\lambda_{\text {ex }}=392.8 \mathrm{~nm}$. For $\mathrm{Tb}^{3+}$, excitation spectra were recorded between $200 \mathrm{~nm}$ and $500 \mathrm{~nm}$ by monitoring the $\left[\mathrm{Tb}^{3+}\right]{ }^{5} \mathrm{D}_{4} \rightarrow{ }^{7} \mathrm{~F}_{5}$ emission at $\lambda_{\text {em }}=540 \mathrm{~nm}$ (spectral bandwidth $=2 \mathrm{~nm}$ ). Emission of $\mathrm{Tb}^{3+}$ in the 410 $700 \mathrm{~nm}$ range, with spectral bandwidth of $2 \mathrm{~nm}$, under selected excitation in the $\left[\mathrm{Tb}^{3+}\right]{ }^{7} \mathrm{~F}_{6} \rightarrow{ }^{5} \mathrm{G}_{6}$ transition at $\lambda_{\text {ex }}=379 \mathrm{~nm}$. The transient characteristics of the emitting level ${ }^{5} \mathrm{D}_{4}$ and ${ }^{5} \mathrm{D}_{0}$, respectively, of $\mathrm{Tb}^{3+}$ and $\mathrm{Eu}^{3+}$ were investigated with the phosphorimeter FL-1040, equipped with a UV xenon flash tube. Emission decays were analyzed at chosen $\lambda_{\mathrm{ex}}$ and $\lambda_{\mathrm{em}}$ on a time interval up to $8 \mathrm{~ms}$. The analysis was made in quadruplicate for colloids prepared in $\mathrm{H}_{2} \mathrm{O}$ and in triplicate for colloids prepared in $\mathrm{D}_{2} \mathrm{O}$, and the results are reported in terms of mean \pm standard deviation. The time resolution imposed by the apparatus in the experimental conditions employed is $30 \mu \mathrm{s}$.

\section{Evaluation of cell-targeting}

This work was performed on both ZR-75-1 and T-47-D (provider: ATCC) breast carcinoma cells; the latter being known to over-express folate receptors on their surface, as opposed to the former. ${ }^{16,17}$ Cells were cultivated in IMDM and RPMI, respectively, with $5 \%$ fetal calf serum, $1 \%$ antibiotics.

The evaluation of cell-targeting ability was based on measuring the amount of intracellular $\mathrm{Ca}^{2+}$ and $\mathrm{Eu}^{3+}$ contents found in these cancer cells after a specific contact time with the colloidal nanoparticles, either associated to FA or not. The tests were performed by the ICELLTIS Company (Verniolle, France), based on an already published protoco $1^{18}$ aimed at determining intracellular ionic contents: $24 \mathrm{~h}$ after seeding, the colloid was added to the cells during a contact time set to $24 \mathrm{~h}$. The concentration of nanoparticles in the culture medium was $1.5 \mathrm{mg} / \mathrm{ml}$. After thorough washing with PBS buffer, the cells were quantified and centrifuged. The residual pellets could then be dissolved in $\mathrm{HCl}$ $(37 \%)$ and incubated for $30 \mathrm{~min}$ at $80^{\circ} \mathrm{C}$, in view of quantification of the $\mathrm{Eu}$ and $\mathrm{Ca}$ contents by ICPAES (analyses performed by the MARION TECHNOLOGIES Company, Verniolle, France). Taking into account the cell washing/centrifugation steps in the presence of an aqueous buffer solution (PBS), the possibilities to have either remaining traces of europium or calcium ions "solely" adsorbed on the cells membrane, or to retain particles merely associated to the cells surface (but not internalized) appear most unlikely taking into account the solubility character of the $\mathrm{Ca}^{2+}$ and $\mathrm{Eu}^{3+}$ ions in aqueous media as well as the high energy engaged in the centrifugation step. Therefore, the $\mathrm{Ca}$ and $\mathrm{Eu}$ contents drawn from tests realized in the presence of the $\mathrm{Ca}$ - and Eu-containing colloidal nanoparticles are expected to be only representative of the internalized particles.

As is commonly done in such cell uptake tests, a negative control was carried out in the absence of nanoparticles, being thus representative of regular cell status. At no time were the control cells in contact with any europium-containing compound; and the unique external calcium ions in contact with control cells was that contained in the cell media (RPMI: [Ca] $\sim 0.6 \mathrm{mM}$, or IMDM $[\mathrm{Ca}] \sim 1.49 \mathrm{mM}$ ). The calcium content found in control cells relates to the calcium contained in the intracellular fluid. As expected, control cells did not show any europium content.

All experiments were performed in triplicate. Data are presented as mean \pm standard deviation.

\section{Results and discussion}

\section{Physico-chemistry / luminescence aspects}

The hybrid apatite-based europium-doped suspensions prepared in this work were fully characterized in a previous work, ${ }^{7}$ and only the main physico-chemical data will be recalled here for the sake of completeness. 
Figures 1 and 2, respectively, report an XRD pattern and an FTIR spectrum, typical of such colloidal nanoparticles (functionalized with AEP), in comparison with non-colloidal (AEP-free) counterparts. These data point out in particular the apatitic nature of the particles (the main XRD diffraction lines corresponding to hydroxyapatite, space group $\mathrm{P}_{3} / \mathrm{m}$ (hexagonal), are added on Figure 1). The presence of AEP molecules associated with the apatite phase is at the origin of a decrease in crystallinity state for the apatite phase, as indicated by Figure 1, which may be related to the occupation of crystal growth sites by AEP molecules during the crystallization process. The functionalization of the particles by AEP can be directly evidenced by FTIR analysis (Figure 2), thanks to the presence of an absorption band at $754 \mathrm{~cm}^{-1}$, which is characteristic of the $\mathrm{P}-\mathrm{O}(\mathrm{C})$ libration mode in systems such as $\mathrm{Ca}(\mathrm{AEP})_{2}$ where a close interaction between AEP molecules (exhibiting one global negative charge at the synthesis $\mathrm{pH}$ ) and $\mathrm{Ca}^{2+}$ ions is involved, as was discussed in previous works. ${ }^{6,7}$ The decreased crystallinity degree of the apatite phase obtained in the presence of AEP (colloidal systems) also leads to a lowered resolution of the FTIR spectrum, as shown in Figure 2 by comparison with an AEP-free system. Moreover, the apatite phase composing the colloidal particles appears less hydroxylated (decreased amount of apatitic $\mathrm{OH}^{-}$ions) as witnessed by the decrease in intensity of the related bands located at 3572 and $631 \mathrm{~cm}^{-1}$. This observation indicates a greater degree of nonstoichiometry for such colloidal apatites, which may, again, be related to the occupation of surface sites by AEP molecules, thus partially hindering the regular nucleation and growth processes.

Zeta potential measurement obtained with these suspensions was systematically found to be positive, close to $+12 \mathrm{mV}$, and this positive value is in good agreement with the presence of grafted AEP molecules, exposing their ammonium $-\mathrm{NH}_{3}{ }^{+}$end-groups toward the solution (while the phosphate end of the AEP molecule interacts with the $\mathrm{Ca}^{2+}$ ions). ${ }^{6}$ In contrast, non-colloidal (i.e. AEP-free) apatite leads to zeta potential values close to $-10 \mathrm{mV}$.

Chemical analyses indicated that the $(\mathrm{Ca}+\mathrm{Eu}) / \mathrm{P}$ mole ratio of the apatite phase was close to 1.60 , with an AEP/apatite ratio of 0.63 . The experimental value of the $\mathrm{Eu} /(\mathrm{Ca}+\mathrm{Eu})$ mole ratio was $2.03 \mathrm{~mol} \%$.

DLS experiments (Figure 3, curve (a)) run on the asprepared suspensions confirmed the nanometer-scale dimensions of the particles, with a mean particle size of $35 \mathrm{~nm}$ (monomodal size distribution). DLS measurements performed after purification by dialysis (as detailed elsewhere) ${ }^{15}$ followed by the addition of HMP (up to $\mathrm{pH}$ stabilization at 7.4) led to a slight increase of the mean particle size close to $40.0 \mathrm{~nm}$ (see Figure 3, curve (b)). This size scale, significantly lower than $100 \mathrm{~nm}$, is thus in a convenient range in view of intracellular applications.

Europium was used in this system due to several potential advantages: europium salts generally exhibit a low toxicity ${ }^{19,20}$ (especially when it is used in very small amounts as is the case in the present

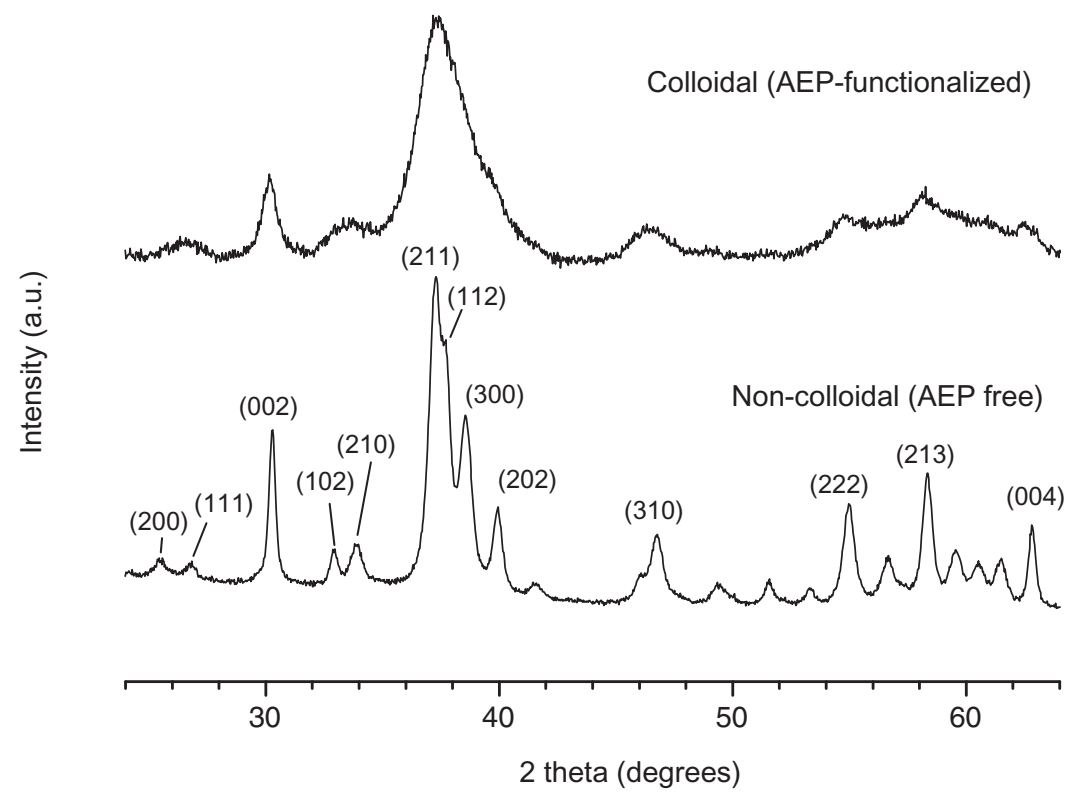

Figure I. Typical XRD pattern for colloidal biomimetic apatite (AEP-functionalized, prepared at $100^{\circ} \mathrm{C}$, and $\mathrm{pH} 9.5$ ), and for a noncolloidal (AEP-free) counterpart with main XRD line indexation. XRD: X-ray diffraction; AEP: 2-aminoethylphosphoric acid. 
contribution); it has a luminescence in the visible spectrum, with a long luminescence lifetime; and it allows the study of biological tissues due to its possible excitation in a low-energy domain (in or near the domain of visible light). Moreover, this element can be introduced in the apatite structure thus conferring intrinsic luminescence properties. These various aspects then enable one to consider europium as a particularly favorable element for luminescence applications in biology or medicine.

Typical excitation and emission spectra for the Eudoped colloids developed here are reported in Figure 4. It is worth noting here that Eu-free samples did not present any luminescence line features as only a diffuse background due to the calcium phosphate matrix was noticed (see background on Figure 4). Moreover, this background emission is only due to short-lived luminescence events as it disappears under time-resolved observation conditions.

The excitation and emission lines reported in Figure 4 are characteristic of the luminescence behavior of $\mathrm{Eu}^{3+}$ ions. ${ }^{21}$ In particular, the main luminescence maxima are localized here in the ranges 583-603, 605-627 and 685-715 $\mathrm{nm}$ and can be assigned, respectively, to the $\left[\mathrm{Eu}^{3+}\right] \quad{ }^{5} \mathrm{D}_{0} \rightarrow{ }^{7} \mathrm{~F}_{1}, \quad{ }^{5} \mathrm{D}_{0} \rightarrow{ }^{7} \mathrm{~F}_{2}$ and ${ }^{5} \mathrm{D}_{0} \rightarrow{ }^{7} \mathrm{~F}_{4}$ transitions. The broad luminescent background can be assigned to the photoluminescence of the apatite matrix itself. The luminescence decay

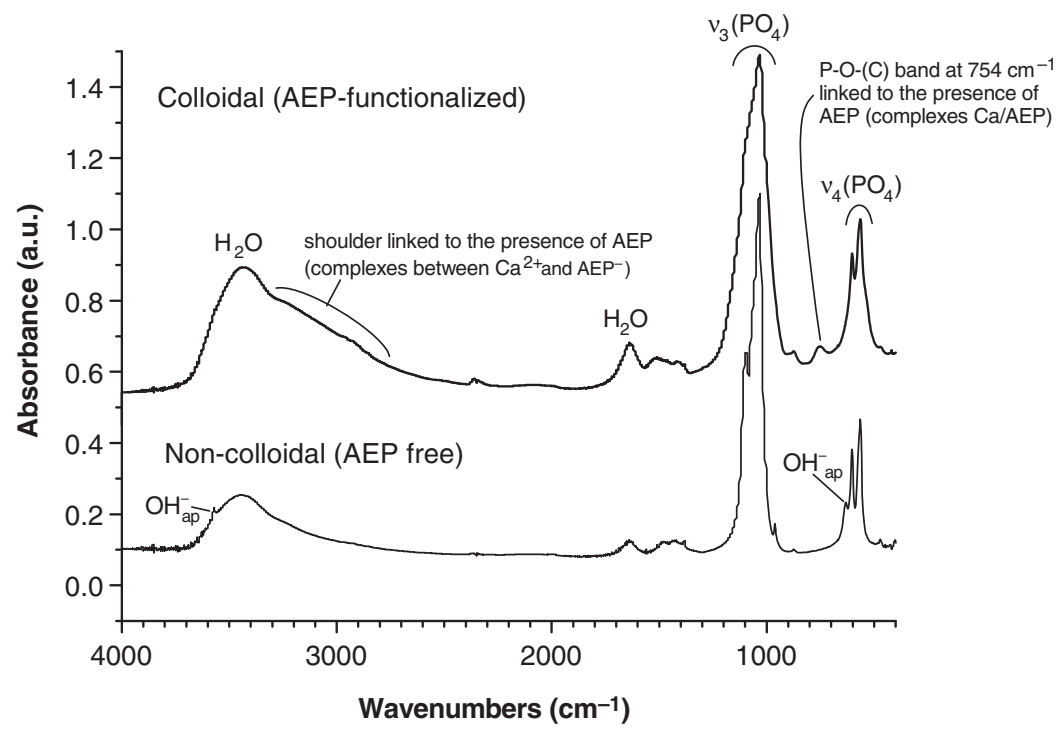

Figure 2. FTIR spectrum for colloidal biomimetic apatite (AEP-functionalized, prepared at $100^{\circ} \mathrm{C}$ and $\mathrm{pH}$ 9.5), and for a non-colloidal (AEP-free) counterpart. FTIR: Fourier-transform infrared; AEP: 2-aminoethylphosphoric acid.

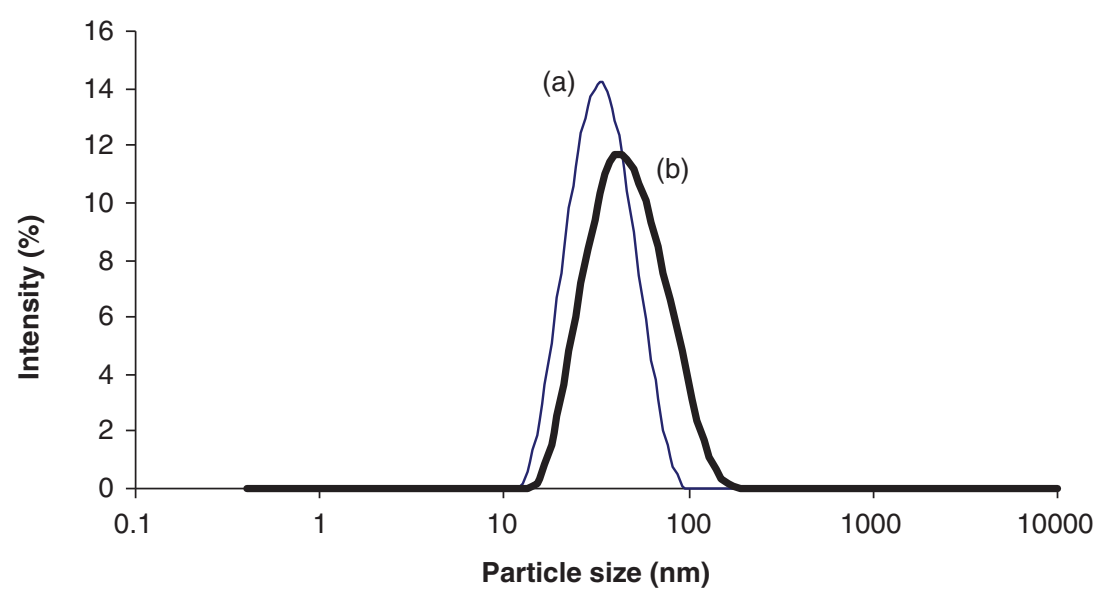

Figure 3. Particle size distributions from dynamic light scattering (DLS). Curve (a): as-synthesized colloid, curve (b): colloid after purification by dialysis and hexametaphosphate (HMP) addition. 
curve, under excitation at $393 \mathrm{~nm}$, with emission monitored at $611.5 \mathrm{~nm}$ is shown on Figure 5. It could be fitted by a mono-exponential decay function and the lifetime value $\left(\tau_{\text {obs }}\right)$ was found to reach $1.34 \pm 0.14 \mathrm{~ms}$. Faster events observed in the first $100 \mu$ s of decay have not been taken in the fit. This value is noticeably larger than the luminescence lifetime of biological tissue auto-fluorescence (of the order of the nanosecond), thus enabling one to envision the analysis of biological materials over extended periods of time and/or the use of time-resolved luminescence equipment (e.g. in view of cell sorting).

Taking into account the energy gap $\Delta \mathrm{E}_{\mathrm{Eu} 3+}$ corresponding to the $\left[\mathrm{Eu}^{3+}\right]{ }^{5} \mathrm{D}_{0} \rightarrow{ }^{7} \mathrm{~F}_{\mathrm{J}}$ transitions, around

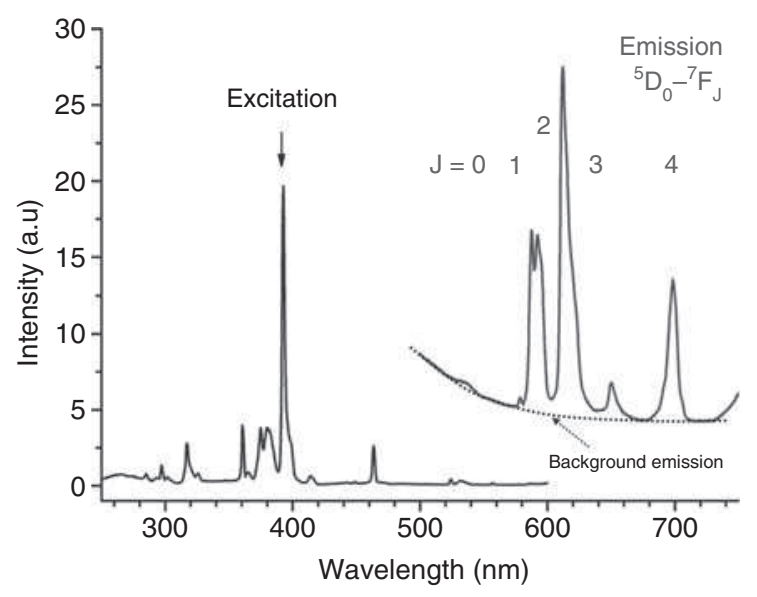

Figure 4. Excitation $\left(\lambda_{\mathrm{em}}=612 \mathrm{~nm}\right)$ and emission $\left(\lambda_{\text {ex }}=392.8 \mathrm{~nm}\right)$ spectra for Eu-doped apatite-AEP colloids (spectra uncorrected for the spectral response of the apparatus), and background emission level due to the calcium phosphate matrix. AEP: 2-aminoethylphosphoric acid.
$15,000 \mathrm{~cm}^{-1}$, one possible origin of non-radiative deexcitation could be through the vibration of $\mathrm{O}-\mathrm{H}$ oscillators $\left(v \sim 3500 \mathrm{~cm}^{-1}\right)$ located at the vicinity of the $\mathrm{Eu}^{3+}$ luminescent centers. Indeed, $\Delta \mathrm{E}_{\mathrm{Eu} 3+}$ happens to be close from the 4 th vibrational harmonic of $\mathrm{O}-\mathrm{H}$ oscillators. In order to examine these aspects in more details, an additional synthesis experiment was carried out by replacing (deionized) $\mathrm{H}_{2} \mathrm{O}$ by deuterated water $\left(\mathrm{D}_{2} \mathrm{O}\right)$, which has the advantages of having the same physico-chemical properties as $\mathrm{H}_{2} \mathrm{O}$ but for which $\mathrm{O}-\mathrm{H}$ vibrators are replaced by $\mathrm{O}-\mathrm{D}$, having a noticeably lower vibration frequency. In these conditions, only the 5th vibrational harmonic of O-D may interact with $\Delta \mathrm{E}_{\mathrm{Eu} 3+}$, thus limiting the probability for vibrational de-excitation to occur, as compared to $\mathrm{O}-\mathrm{H}$. The measure of the characteristic luminescence decay time for this deuterated suspension led to a value $(2.90 \pm 0.29 \mathrm{~ms})$ significantly greater than for a nondeuterated suspension as illustrated in Figure 5.

The so-called "Horrocks formula" has been established by measuring the ${ }^{5} \mathrm{D}_{0}$ exponential decay rate constants of complexes prepared in light and heavy water. $^{22,23}$ It predicts the number of water molecules (which may also be seen as a pair of $\mathrm{OH}$ groups) per $\mathrm{Eu}^{3+}$ emitter (in the first coordination shell):

$$
n_{\mathrm{H}_{2} \mathrm{O}}=\frac{n_{\mathrm{OH}}}{2} \approx 1.05\left[\frac{1}{\tau_{\mathrm{H}_{2} \mathrm{O}}}-\frac{1}{\tau_{\mathrm{D}_{2} \mathrm{O}}}\right]
$$

The application of this equation in our case leads to $0.86 \mathrm{OH}$ groups per europium ion. The location of $\mathrm{Eu}^{3+}$ ions in the apatite structure has been investigated in the literature and its preference for $\mathrm{Ca}(\mathrm{II})$ sites of the apatite structure was reported. ${ }^{24}$ Interestingly, these crystallographic sites are known to surround the socalled "apatitic tunnels" that contain the $\mathrm{OH}^{-}$ions of

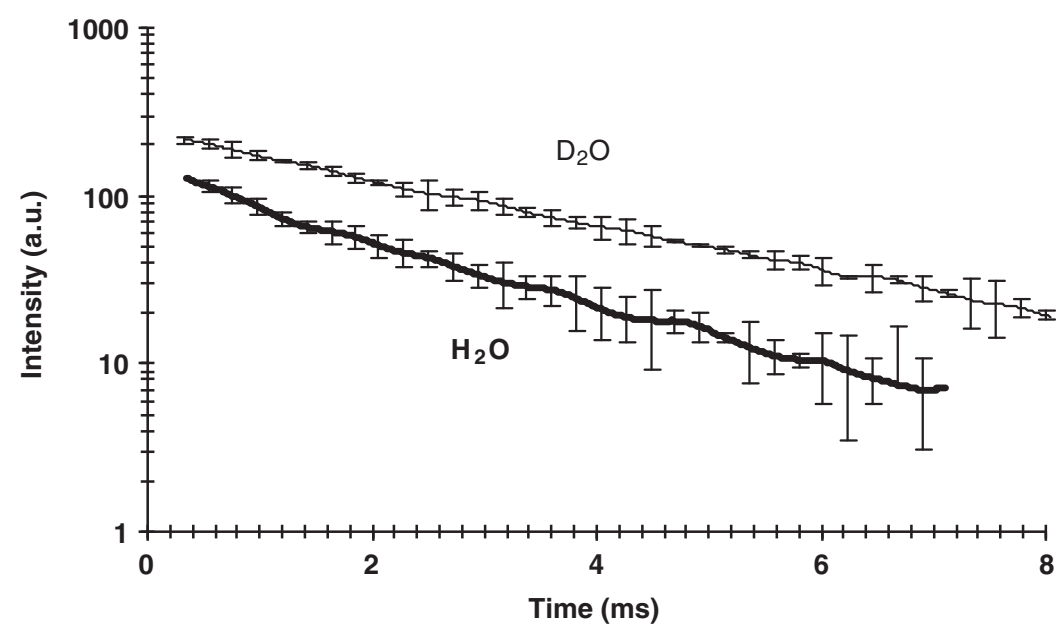

Figure 5. Luminescence decays for a Eu-doped suspension prepared in deuterated or in non-deuterated water. 
the apatite structure, as well as possibly some water molecules. Therefore, the presence of these species, implying $\mathrm{O}-\mathrm{H}$ vibrators, may be at the origin of the partial non-radiative de-excitation of Eu-doped apatite-based colloids.

The luminescence efficiency " $\varepsilon$ " can be defined by the relation $\varepsilon=\tau_{\mathrm{obs}} / \tau_{\mathrm{rad}}$, where $\tau_{\mathrm{obs}}$ is the experimentally observed luminescence decay time (thus implying both radiative and non-radiative de-excitation) and where $\tau_{\mathrm{rad}}$ is defined by $\tau_{\mathrm{rad}}=1 / \mathrm{W}_{\mathrm{rad}}, \mathrm{W}_{\mathrm{rad}}$ being the total ${ }^{5} \mathrm{D}_{0}$ radiative rate. This value may be calculated from the ${ }^{5} \mathrm{D}_{0} \rightarrow{ }^{7} \mathrm{~F}_{\mathrm{J}}$ emission spectrum and has proven to be very convenient for comparing different kinds of compounds containing $\mathrm{Eu}^{3+}$, especially when absorption data are not easily available (e.g. due to the turbidity of the suspensions, leading to a non-negligible amount of diffused light). It has been used in the literature in numerous cases, as shown for instance in review articles. $^{25,26}$

The integrated area of a ${ }^{5} \mathrm{D}_{0} \rightarrow{ }^{7} \mathrm{~F}_{\mathrm{J}}$ emission band, denoted $\mathrm{I}\left({ }^{5} \mathrm{D}_{0} \rightarrow{ }^{7} \mathrm{~F}_{\mathrm{J}}\right)$, is directly proportional to the corresponding radiative rate $W_{0-\mathrm{J}}$, to the number of active ions in the emitting volume, and to a number of instrumental parameters hard to estimate; but this last difficulty can be overcome by considering the intensities relatively to the value of $\mathrm{I}\left({ }^{5} \mathrm{D}_{0} \rightarrow{ }^{7} \mathrm{~F}_{1}\right)$, taken as a reference: the ${ }^{5} \mathrm{D}_{0} \rightarrow{ }^{7} \mathrm{~F}_{1}$ emission is indeed purely magnetic dipolar in nature and its radiative rate does not depend on the local field imposed by the environment. It has been calculated, from theory, that $W_{0-1}=14.65 n^{3}$ (value expressed in $\mathrm{s}^{-1}$ ) where $n$ is the refractive index of the medium. ${ }^{27}$ Then:

$$
\frac{I\left({ }^{5} D_{0} \rightarrow{ }^{7} F_{\mathrm{J}}\right)}{I\left({ }^{5} D_{0} \rightarrow{ }^{7} F_{1}\right)}=\frac{W_{0-\mathrm{J}}}{W_{0-1}}
$$

The total ${ }^{5} \mathrm{D}_{0}$ radiative rate $\mathrm{W}_{\text {rad }}$ is the sum of the $W_{0-\mathrm{J}}$ contributions over $\mathrm{J}=0-4$ (it is, reasonably, assumed that ${ }^{5} \mathrm{D}_{0} \rightarrow{ }^{7} \mathrm{~F}_{5,6}$ have negligible intensities). The emission spectra were corrected for the instrumental response versus wavelength and the emission background was subtracted.

This protocol has been applied here taking $n=1.33$ as the refractive index (that of water), and gives $W_{\text {rad }}=162 \mathrm{~s}^{-1}\left(\tau_{\mathrm{rad}}=6.17 \mathrm{~ms}\right)$. The estimated efficiency for the $\mathrm{Eu}^{3+}$-doped apatite colloid tested is therefore of $22 \%$. Of course the numerical values of $\tau_{\text {rad }}$ and therefore that of $\varepsilon$ greatly depend upon the value chosen for $\mathrm{n}$. Taking into account the rather low concentration in nanoparticles in the colloids tested in this study, the approximation of the value $n=1.33$ seems reasonable. In their study on polyphosphate colloidal systems, ${ }^{28}$ Dias Filho et al. also considered that the medium was essentially water $(n=1.33)$ and they calculated the maximum efficiency of $22 \%$ when the europium ions are well encapsulated by polyphosphate chains. As noticed in that paper, the ${ }^{5} \mathrm{D}_{0}$ efficiency of about $20 \%$ is quite high in water solvent.

In the case of apatite colloids, the main non-radiative de-excitation pathway is probably via coupling with $\mathrm{OH}$-containing species located in the apatitic tunnels (mostly in the form of $\mathrm{OH}^{-}$ions) and this number of hydroxide ions will probably not be easy to lower if one intends to keep the synthesis at moderate temperature. Therefore, it was interesting to check here, in a preliminary approach, the possibility to substitute europium by another rare earth element less prone to $\mathrm{O}-\mathrm{H}$ vibrational de-excitation. This is especially the case for terbium ions, $\mathrm{Tb}^{3+}$, which also have a luminescence signature in visible light, but in the green domain. The possibility to incorporate $\mathrm{Tb}^{3+}$ ions in apatitic lattices has already been verified in the literature, ${ }^{29}$ but in the case of other types of formulations (e.g. involving DNA), and it thus appeared interesting at this stage to widen the perspectives of research of the AEP-stabilized biomimetic apatite colloids prepared here from easily handled ionic salts.

Therefore, colloidal suspensions doped with $\mathrm{Tb}^{3+}$ ions were prepared, following the same protocol as for $\mathrm{Eu}^{3+}$, and their physico-chemical and luminescence properties were checked.

The substitution of $\mathrm{Eu}$ by $\mathrm{Tb}$ was found to lead to no major modification in the general characteristics of the apatite phase. Luminescence features were found (Figure 6) to be characteristic of the excitation and emission of trivalent terbium ions. As was noticed above in the case of europium, Tb-free samples did not exhibit any luminescence line features as only the calcium phosphate diffuse background was detected (see background level on Figure 6).

The maximum excitation of $\mathrm{Tb}^{3+}$ was founded at $379 \mathrm{~nm}$, thus close to the visible light domain. The emission spectrum (recorded under excitation at $379 \mathrm{~nm}$ ) showed peaks resulting from the $4 \mathrm{f}-4 \mathrm{f}$ transition of the $\mathrm{Tb}^{3+}$ ions: $\left[\mathrm{Tb}^{3+}\right]{ }^{5} \mathrm{D}_{4} \rightarrow{ }^{7} \mathrm{~F}_{6}$ (at $488 \mathrm{~nm}$ ), ${ }^{5} \mathrm{D}_{4} \rightarrow{ }^{7} \mathrm{~F}_{5}$ (at $545 \mathrm{~nm}$ ), ${ }^{5} \mathrm{D}_{4} \rightarrow{ }^{7} \mathrm{~F}_{4}$ (at $586 \mathrm{~nm}$ ), and ${ }^{5} \mathrm{D}_{4} \rightarrow{ }^{7} \mathrm{~F}_{3}$ (at $623 \mathrm{~nm}$ ). A relatively intense emission background, due to the apatite matrix, was observed for the Tb-doped colloid, as with the Eu-doped system. Observed in same experimental conditions, the $\mathrm{Tb}^{3+}$-doped colloid emits with about the same intensity (integrated over the range $470-720 \mathrm{~nm}$ ) as the $\mathrm{Eu}^{3+}$-doped system. The $\left[\mathrm{Tb}^{3+}\right]{ }^{5} \mathrm{D}_{4}$ decay time was also found to be encouragingly large, close to $2.15 \pm 0.21 \mathrm{~ms}$. Forthcoming works will then be devoted to analyze further the Tb-doped systems and to compare the luminescence advantages and drawbacks of these Eu- and Tb-doped systems once incorporated in cells. This will be the object of future reports. 


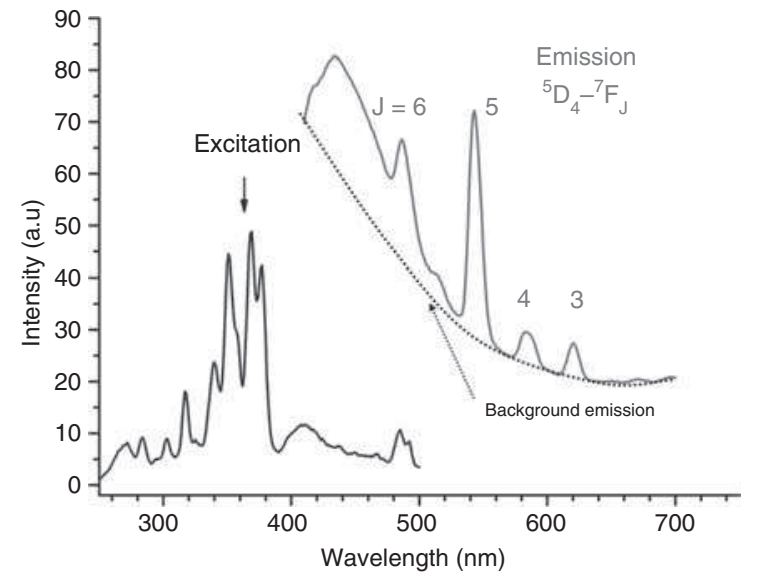

Figure 6. Excitation $\left(\lambda_{\mathrm{em}}=540 \mathrm{~nm}\right)$ and emission $\left(\lambda_{\text {ex }}=379 \mathrm{~nm}\right)$ spectra for Tb-doped apatite-AEP colloids (spectra uncorrected for the spectral response of the apparatus), and background emission level due to the calcium phosphate matrix. AEP: 2-aminoethylphosphoric acid.

\section{Drying and re-suspension aspects}

Apart from the luminescent properties of such colloids (e.g. in view of medical imaging), another major aspect regarding the development of imaging nanoprobes (or drug delivery nanosystems) concerns their ability to be stored for extended periods of time without alteration of their characteristics. Indeed, the ageing of colloidal suspensions may lead to an aggregation of the constituting nanoparticles. It was thus interesting at this point to investigate the possibility to store our suspensions in a dry state while retaining their initial nanoparticle size. This issue is not trivial since drying processes often lead to the formation of agglomerates of initial particles.

The storage (and sterilization) of powder specimens can be considered as appreciably easier than for liquid suspensions. Therefore, in this work, tests have been undergone by drying and subsequently re-suspending apatite-based colloids (with the objective to preserve an acceptable particle size in view of an intracellular activity).

Attempts based on oven- or freeze-drying of the "as synthesized" colloids followed by a re-immersion in aqueous medium were all found to be unsuccessful as a rapid sedimentation of the system occurred within few seconds. This effect may probably be linked to the high surface energy of apatite nanocrystals, which are prone to interact strongly with each other, upon elimination of water, in view of minimizing the total surface energy of the system.

In this context, experiments were then run by freezedrying the suspensions after addition of glucose in the medium. Very interestingly, the two largest concentrations tested were found to lead to a successful re-dispersion of the nanoparticles, and no sedimentation of the suspension occurred during the tests. On the contrary, glucose concentration of $3.7 \mathrm{mg} / \mathrm{ml}$ only partially permitted to re-suspend the colloidal particles. These observations were further quantified by DLS measurements, indicating in this latter case a bimodal size distribution with a mean hydrodynamic diameter close to $315 \mathrm{~nm}$; while the 2 largest glucose concentrations tested led to a mean particle size of ca. $39 \mathrm{~nm}$ (monomodal), which is similar to the case of the suspension obtained after purification by dialysis and addition of HMP (mean $D_{h}$ value of $40 \mathrm{~nm}$ ). These results can be explained by the need to create a deepenough (water-soluble) glucose matrix during (freeze)drying so as to efficiently hinder the aggregation of the particles during water elimination. Alike the mean size of the particles, it is worthwhile signaling that the other physico-chemical characteristics of the nanoparticles were not modified by the presence of glucose at the 11.1 and $18.5 \mathrm{mg} / \mathrm{ml}$ concentrations, which was ascertained by FTIR and XRD analyses. Therefore, these findings reveal the possibility to efficiently store such apatite-based hybrid colloids in a dry state, upon addition of a water-soluble matrix such as glucose, while conserving their full characteristics and keeping the possibility to re-suspend them when appropriate (e.g. in a biological laboratory or in peri-operative procedures).

\section{Evaluation of cell-targeting effects by way of FA grafting}

As reminded in the introduction section, a previous work showed that FA could be successfully grafted on the surface of AEP-stabilized biomimetic apatite nanoparticles, and our data indicated the existence of a clear $\mathrm{FA}_{-} \mathrm{Ca}^{2+}$ interaction, without modifying the main physico-chemical characteristics of the apatite colloidal nanoparticles. ${ }^{5}$ These findings are of particular relevance since FA is a well-known cell-targeting agent for cells that overexpress folate receptors (generally denoted "FR") on their surface membrane, which is the case for several types of cancer cells (e.g. some breast or ovarian cancer cells for instance). ${ }^{30}$ It is worthwhile reminding here that these FR (displaying a high affinity for FA or folate molecules) should not be confounded with the reduced folate receptors (RFC) that are usually present on the surface of normal cells but which interact with the reduced forms of folate molecules (e.g. dihydro- or tetrahydro-folates). ${ }^{31}$

In the present contribution, it was therefore interesting to go one step beyond, by analyzing whether this FA-grafting on the surface of apatite nanoparticles could lead to a marked targeting effect towards cells 


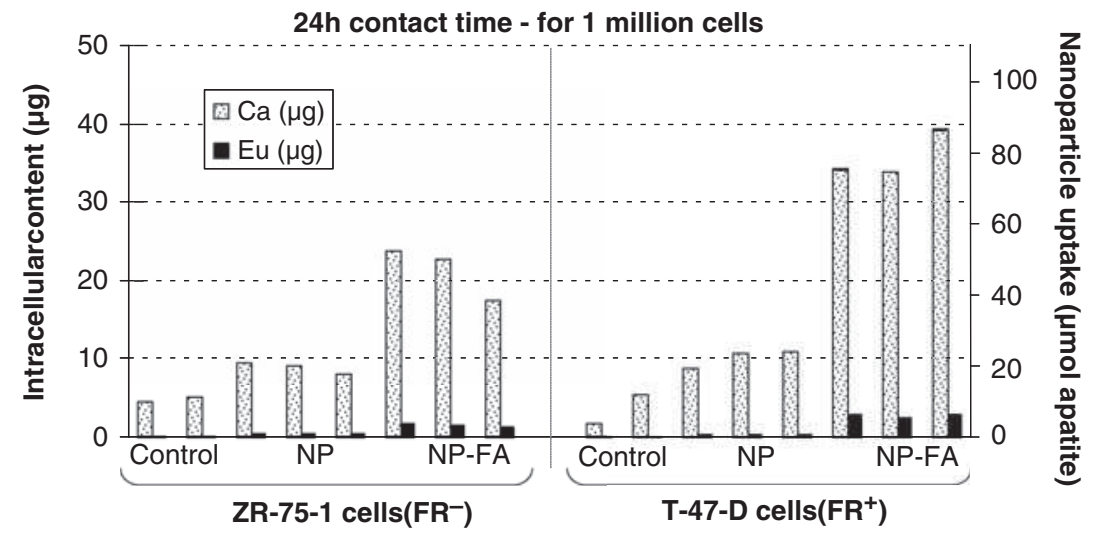

Figure 7. Cellular uptake of nanoparticles without folic acid functionalization (NP) and with folic acid grafting (NP-FA), for ZR-75-I $\left(F R^{-}\right)$and T-47-D $\left(\mathrm{FR}^{+}\right)$breast carcinoma cells. Data are expressed in $\mathrm{Ca}$ and Eu intracellular contents after contact time of $24 \mathrm{~h}$.

that overexpress FR, as compared to cells that do not specifically expose FR on their surface membrane. In this context, we chose here to work on two types of breast cancer cells: T-47-D (which overexpress FR, denoted by the attribute "FR" $\left.{ }^{+}\right)^{16}$ and ZR-75-1 breast carcinoma cells (which do not naturally overexpress FR, denoted "FR" $\left.{ }^{-\prime}\right) .{ }^{17}$ This study was specifically run on the luminescent (Eu-doped) colloids as they represent the final types of systems to be used in the imaging application envisioned here.

In vitro experiments were then initiated by contacting (for $24 \mathrm{~h}$ ) each type of cells with the colloidal nanoparticles, enriched or not with FA. The initial cell seeding was realized with 600,000 cells, and the cell counts after $24 \mathrm{~h}$ of tests were all in the range $600,000-880,000$, which indicates in particular that no significant cell death was detected. Additionally, no direct correlation between the cell count and the tests conditions (cell types, presence or absence of nanoparticles, presence or absence of FA in the formulation of the colloids) was evidenced.

The interaction between the cells and the colloidal nanoparticles was then followed by measuring the intracellular $\mathrm{Ca}^{2+}$ and $\mathrm{Eu}^{3+}$ contents via coupled plasma atomic emission spectroscopy (ICP-AES), after cell treatment as explained in the experimental section. This type of ICP-based protocols has already been exploited in the literature $^{18}$ for enabling the determination of intracellular nanoparticle uptakes. Figure 7 reports the data obtained, both in terms of measured $\mathrm{Ca}$ and $\mathrm{Eu}$ intracellular contents (left $\mathrm{Y}$-axis) and in terms of the corresponding nanoparticle uptake (right axis, expressed in $\mu \mathrm{mol}$ of apatite). This nanoparticle uptake was quantified directly from the measured intracellular $\mathrm{Ca}$ and $\mathrm{Eu}$ contents found by ICP, based on the preliminary knowledge of the $\mathrm{Ca}$ and $\mathrm{Eu}$ contents found in the colloidal nanoparticles themselves.
The control experiments, carried out in the absence of nanoparticles (nor europium) in the medium, show a rather similar and low initial calcium content $(<5 \mu \mathrm{g}$ per million cells) for both cell types as well as the absence of intracellular europium ions, as expected. For cells contacted with nanoparticles without functionalization by FA (NP), the analysis of intracellular Ca and $\mathrm{Eu}$ values shows, in the conditions of the tests, that both ZR-75-1 and T-47-D cells were able to internalize some nanoparticles, in similar amounts independently of the presence of FR receptors on the cells. However, this amount remains limited to ca. $20 \mu \mathrm{mol}$ of colloidal nanoparticles per million cells (Figure 7). On the contrary, FA-grafted nanoparticles showed a greater tendency to internalize the colloidal apatite-based nanoparticles, for both cell types, but with in a much more pronounced manner for the FR-positive T-47-D cells, where the NP uptake is 3 - to 4-fold greater than in the absence of FA functionalization. Also, the cellular uptake remains 1.5 to 2 times greater for T-47-D cells (reaching up to $86.2 \mu \mathrm{mol}$ of colloidal nanoparticles per million cells) as compared to ZR-75-1 cells which do not overexpress FRs.

These findings point out the more selective uptake of FA-functionalized apatite-based nanoparticles by the $\mathrm{FR}^{+}$-cell type (here represented by T-47-D cells), thus evidencing some targeting abilities for such colloidal engineered nanoparticles. This conclusion opens then even wider perspectives aiming at substituting FA by other cell-targeting agents so as to increase further the targeting selectivity.

Another remarkable conclusion of these cellular uptake data is related to the confirmation that the methylpterin-like part of the FA molecules, which is known to play the determining role in the recognition by cells' FR receptors, remained effectively biologically active. The cellular uptake witnessed here is most likely FA-mediated endocytosis, as is generally considered for 
FA-functionalized nanosystems, where the internalization process starts right after recognition of FA by the FR receptors. ${ }^{32}$

\section{Conclusions}

This work brought out some additional details on fundamental and practical aspects concerning AEP-stabilized biomimetic apatite colloidal doped with lanthanide ions $\left(\mathrm{Eu}^{3+}, \mathrm{Tb}^{3+}\right)$. We have in particular unveiled the existence of a partial non-radiative de-excitation process, involving O-H oscillators present at the vicinity of the $\mathrm{Eu}^{3+}$ luminescent centers, and the use of $\mathrm{Tb}^{3+}$ ions was then proposed as a possible alternative so as to limit such luminescence quenching effects.

The use of such colloidal nanoparticles could prove helpful for time-resolved in vitro (e.g. through flow cytometry) or even in vivo experiments, for which long luminescence lifetimes are especially adapted so as to allow the extinction of biological tissues autofluoresence.

We then inspected the possibility to store such colloidal suspensions in a dry state, while preserving an ability to be re-suspended easily in aqueous medium. Our findings indicated that this was made possible, thanks to the addition of glucose in the formulation prior to freeze-drying, so as to lead to a water-soluble glucose matrix surrounding the nanoparticles, thus hindering their aggregation. These results should prove helpful for the storage of such individualized nanoparticles over extended periods of time, while allowing the system to be re-suspended at the moment of use (e.g. for medical imaging purposes).

Finally, FA surface functionalization on the colloidal nanoparticles made it possible to target $\mathrm{FR}^{+}$ cancer cells (tested here on T-47-D breast carcinoma cells) to a significantly greater level than $\mathrm{FR}^{-}$cells (tested here on ZR-75-1 cells). These encouraging results then open exciting perspectives, not only exploiting FA targeting but also enlarging it to other targeting agents susceptible to interact with the surface of biomimetic apatite-based nanoparticles.

\section{Funding}

This research received no specific grant from any funding agency in the public, commercial, or not-for-profit sectors.

\section{References}

1. Powell AC, Paciotti GF and Libutti SK. Colloidal gold: a novel nanoparticle for targeted cancer therapeutics. Method Mol Biol 2010; 624: 375-384.

2. Azzazy HME, Mansour MMH and Kazinierczak SC. From diagnostics to therapy: Prospects of quantum dots. Clin Biochem 2007; 40: 917-927.
3. Hamad I, Al-Hanbali O, Hunter AC, et al. Distinct Polymer Architecture Mediates Switching of Complement Activation Pathways at the NanosphereSerum Interface: Implications for Stealth Nanoparticle Engineering. Acs Nano 2010; 4: 6629-6638.

4. Sofou S. Surface-active liposomes for targeted cancer therapy. Nanomedicine 2007; 2: 711-724.

5. Al-Kattan A, Girod-Fullana S, Charvillat C, et al. Biomimetic nanocrystalline apatites: Emerging perspectives in cancer diagnosis and treatment. Int $J$ Pharmaceut 2012; 423: 26-36.

6. Bouladjine A, Al-Kattan A, Dufour P, et al. New advances in nanocrystalline apatite colloids intended for cellular drug delivery. Langmuir 2009; 25: 12256-12265.

7. Al-Kattan A, Dufour P, Dexpert-Ghys J, et al. Preparation and physicochemical characteristics of luminescent apatite-based colloids. J Phys Chem C 2010; 114: 2918-2924.

8. Combes C and Rey C. Adsorption of proteins and calcium phosphate materials bioactivity. Biomaterials 2002; 23: 2817-2823.

9. Midy V, Rey C, Bres E, et al. Basic fibroblast growth factor adsorption and release properties of calcium phosphate. J Biomed Mater Res 1998; 41: 405-411.

10. Guicheux J, Grimandi G, Trecant M, et al. Apatite as carrier for growth hormone: In vitro characterization of loading and release. J Biomed Mater Res 1997; 34: 165-170.

11. Barroug A and Glimcher MJ. Hydroxyapatite crystals as a local delivery system for cisplatin: adsorption and release of cisplatin in vitro. $J$ Orthopaed Res 2002; 20: 274-280.

12. Al-Kattan A, Errassifi F, Sautereau A, et al. Medical potentialities of biomimetic apatites through adsorption, ionic substitution, and mineral/organic associations: Three illustrative examples. Adv Eng Mater 2010; 12: B224-B33.

13. Ternane R, Trabelsi-Ayedi M, Kbir-Ariguib N, et al. Luminescent properties of Eu3+ in calcium hydroxyapatite. J Luminesc 1999; 81: 165-170.

14. Rothfield L and Finkelstein A. Membrane biochemistry. Annual Rev Biochem 1968; 37: 463-496.

15. Al-Kattan A, Dufour P and Drouet C. Purification of biomimetic apatite-based hybrid colloids intended for biomedical applications: A dialysis study. Coll Surfaces B-Biointer 2011; 82: 378-384.

16. Geszke M, Murias M, Balan L, et al. Folic acid-conjugated core/shell $\mathrm{ZnS}: \mathrm{Mn} / \mathrm{ZnS}$ quantum dots as targeted probes for two photon fluorescence imaging of cancer cells. Acta Biomaterialia 2011; 7: 1327-1338.

17. Dixon KH, Mulligan T, Chung KN, et al. Effects of folate receptor expression following stable transfection into wild-type and methotrexate transport-deficient ZR-75-1 human breast-cancer cells. J Biol Chem 1992; 267: $24140-24147$.

18. Zhang Y, Kohler N and Zhang MQ. Surface modification of superparamagnetic magnetite nanoparticles and their intracellular uptake. Biomaterials 2002; 23: 1553-1561. 
19. Patra CR, Moneim SSA, Wang E, et al. In vivo toxicity studies of europium hydroxide nanorods in mice. Toxicol Appl Pharmacol 2009; 240: 88-98.

20. Haley TJ. Pharmacology and toxicology of rare earth elements. J Pharmaceut Sci 1965; 54: 663-670.

21. Richardson FS. Terbium(III) and europium(III) ions as luminescent probes and stains for biomolecular systems. Chem Rev 1982; 82: 541-552.

22. Horrocks WD, Schmidt GF, Sudnick DR, et al. Laserinduced lanthanide ion luminescence lifetime measurements by direct excitation of metal-ion levels - new class of structural probe for calcium-binding proteins and nucleic-acids. J Am Chem Soc 1977; 99: 2378-2380.

23. Horrocks WD and Sudnick DR. Lanthanide ion probes of structure in biology - laser-induced luminescence decay constants provide a direct measure of the number of metal-coordinated water-molecules. J Am Chem Soc 1979; 101: 334-340

24. Boyer L, Piriou B, Carpena J, et al. Study of sites occupation and chemical environment of $\mathrm{Eu} 3+$ in phosphatesilicates oxyapatites by luminescence. $J$ Alloys Comp 2000; 311: 143-152.

25. Carlos LD, Ferreira RAS, Bermudez VD, et al. Lanthanide-containing light-emitting organic-inorganic hybrids: a bet on the future. Adv Mater 2009; 21: 509-534.
26. Binnemans K. Lanthanide-based luminescent hybrid materials. Chem Rev 2009; 109: 4283-4374.

27. Duarte AP, Gressier M, Menu MJ, et al. Structural and luminescence properties of silica-based hybrids containing new silylated-Diketonato Europium(III) complex. J Phys Chem C 2012; 116: 505-515.

28. Dias FA, Carlos LD, Messadeq Y, et al. Spectroscopic study and local coordination of polyphosphate colloidal systems. Langmuir 2005; 21: 1776-1783.

29. Mondejar SP, Kovtun A and Epple M. Lanthanidedoped calcium phosphate nanoparticles with high internal crystallinity and with a shell of DNA as fluorescent probes in cell experiments. J Mater Chem 2007; 17: 4153-4159.

30. Antony AC. The biological chemistry of folate receptors. Blood 1992; 79: 2807-2820.

31. Spinella MJ, Brigle KE, Sierra EE, et al. Distinguishing between folate receptor-alpha-mediated transport and reduced folate carrier-mediated transport in 11210 leukemia-cells. J Biol Chem 1995; 270: 7842-7849.

32. Kamen BA, Wang MT, Streckfuss AJ, et al. Delivery of folates to the cytoplasm of ma104 cells is mediated by a surface-membrane receptor that recycles. J Biol Chem 1988; 263: 13602-13609. 